\title{
Promoting healthy diet and physical activity in Irish secondary schools: the views of principals and teachers
}

\author{
S. Browne ${ }^{1}$, C. Barron ${ }^{1}$, V. Lambert ${ }^{1}$, D. Susta ${ }^{2}$, A. Staines ${ }^{1}$ and M.R. Sweeney ${ }^{1}$ \\ ${ }^{1}$ NURISH School Nursing \& Human Sciences and ${ }^{2}$ School Health \& Human Performance, Dublin City University, \\ Dublin 9, Republic of Ireland (ROI)
}

Secondary school students spend many of their waking hours in school. Schools are expected to provide both health education and supportive, healthy environments for students. School practices do not always reflect national dietary and physical activity (PA) recommendations for young people ${ }^{1,2}$. This qualitative study examines the views of secondary school principals and teachers in the ROI with regards to the role of the school in nutrition and PA health promotion.

Individual interviews with school principals, and focus groups with teachers, were conducted as part of a larger diet and PA study with adolescents. All interviews were recorded, transcribed and content analysis used to identify the dominant emerging themes

Five principals gave interviews and five focus groups were held with a total of 27 teachers in five schools. Each interview or focus group lasted 30-45 minutes. Principals and teachers feel strongly that schools play an important role in promoting healthy eating and physical activity participation to students. This view was held even though many felt overwhelmed by the increasing demands on schools to fill education gaps on a wide range of social and health topics.

“...So there's a lot of conflicting things whereas in my head I feel that exercise is so important, I feel diet is so important but maybe I'm not doing enough...like the canteen is something separate almost, I'm running an educational establishment and yet, of course this is important because if they're not healthy, nothing else matters in a way..." (principal, School 2)

Many principals and teachers were unhappy with the current situation in their schools. Principals feel resigned to providing some unhealthy food choices at school in order to feed a large number of students in a short space of time, to compete with local shops, and ensure that on-site independent food operators are profitable. The demand for schools to provide convenient, affordable foods to students has increased in recent years. Teachers and principals feel they cannot commit time and resources to monitoring and enforcing restrictions on certain foods, especially since students are also free to bring foods and beverages from home or local shops. While some healthy options were available in participating schools, both principals and teachers described failed attempts at introducing variety in the past.

Time and over-crowded curricula were reasons given for not meeting recommendations for the provision of physical education (PE) classes. PE teachers reported difficulty with participation among girls and senior students. Extra-curricular sports timetables varied by school and depended upon volunteer coaches from the teaching staff.

Lack of time was a barrier consistently reported by all principals to implementing health promotion initiatives at school. Realistic interventions for schools, as suggested by participants in this study, include applied education modules for the junior and transition year curricula, whole-school food and PA policies, changes to foods sold in school shops, canteens and vending machines and engaging non-sporty students in alternative activities in PE.

1. Kelly C, Clerkin P, Nic Gabhainn S (2010) Health Education 110, 336-350.

2. Woods CB, Tannehill D, Quinlan A et al. (2010) The CSPPA Study Dublin City University \& The Irish Sports Council, Dublin, Ireland. 